Volume 6, Issue 1, January 2021, pp. 32 - 45

DOI: $10.23917 /$ jramathedu.v6i1.11198

p-ISSN: 2503-3697, e-ISSN: 2541-2590

\title{
The effectiveness of goal-free problems for studying triangle similarity in collaborative groups
}

\author{
Pratama Wahyu Purnama, Endah Retnowati* \\ Department of Mathematics Education, Yogyakarta State University, Indonesia \\ *Corresponding Author: e.retno@uny.ac.id
}

ARTICLE INFO

Article history:

Received: 18 June 2020

Revised: 28 September 2020

Accepted: 12 October 2020

Published online: 16

December 2020

Published regularly: January 2021

Keywords:

Geometry, goal-free problems, cognitive load, collaborative learning

\section{ABSTRACT}

Similarity is a topic in Geometry which investigates similar elements of a plane. This topic has a high complexity that generates cognitive load in working memory. A deep understanding of the concept is needed to solve similarity problems. Based on cognitive load theory, learning by goal-free problems is suggested since it can minimize cognitive load. This research examined the effectiveness of presenting similarity inquiries using goalfree problems for learning by collaboration. Using a factorial design: 2 presentation techniques (goal-free vs. goal-given problems) $\mathrm{x} 2$ groupings (collaborative vs. individual) in authentic classrooms, the experiment consisted of four consecutive phases: introductory, learning phase, retention test, and transfer test. One-hundred eleven eighth-graders from four classrooms in a junior high school in Yogyakarta, Indonesia, served as research participants. The findings showed that students who were learning using goal-free problems possessed significantly higher scores of retention and transfer tests, as well as experience lower cognitive load during both tests. On the contrary, it was found that studying individually yielded a significantly higher transfer score than studying collaboratively. Since there was no interaction effect, it may be concluded that goal-free problems can be effective for either collaborative or individual learning.

(C) 2020 Universitas Muhammadiyah Surakarta

\section{Introduction}

Problem-solving is the major goal and focus of mathematics instruction (Schoenfeld, 2016). Problem-solving is also a skill that should be improved among students in learning mathematics (Retnowati, Ayres, \& Sweller, 2010). Problem-solving may be developed during collaboration (Kirschner, Sweller, Kirschner, \& Zambrano, 2018). However, there has not been a single strategy known able to build this skill.

Problem-solving is typically used for problems with a high level of complexity. Geometry is one of the materials in mathematics with high complexity (Irwansyah \& Retnowati, 2019). The triangle similarity is a topic in Geometry, which requires students to investigate similar elements of a plane. Triangle similarity might be categorized as a complex material because it requires a minimum of four steps to finding a solution. The first step is the identification of the corresponding sides and problems. The second step is making equations from the corresponding sides. The next step is solving equations, and the final step is finding the solutions of the problems (Tasari, 2011:18-23). A deep

To cite this article:

Purnama, P. W., \& Retnowati, E. (2020). The effectiveness of goal-free problems for studying triangle similarity in collaborative groups. JRAMathEdu Uournal of Research and Advances in Mathematics Education), 6(1), 32-45. https://doi.org/10.23917/jramathedu.v6i1.11198 
understanding of the concept is needed to solve the problem-solving on triangle similarity material. This topic is usually learned by Year 9 students (BSNP, 2006).

The process of solving problems can be described using human cognitive architecture. The human cognitive architecture consists of three major components: sensory memory, working memory, and long-term memory (Sweller, Ayres, \& Kalyuga, 2011). New information which enters the sensory memory will be processed and given meaning by the working memory through presenting relevant knowledge stored in the long-term memory, which will then integrate the new and old information. Information that has a process in working memory will be stored back in the long-term memory. Working memory is a part of the human cognitive architecture used as a place to process information received by an individual before the information is passed on to the long-term memory, which has an unlimited capacity (Sweller et al., 2011). In contrast, working memory has a limited capacity (Miller, 1956) and limited duration as it can only hold new information for about 20 seconds (Peterson \& Peterson, 1959).

Solving complex problems generate cognitive load in the working memory. Geometry is one of the materials in mathematics that has high complexity (Irwansyah \& Retnowati, $\underline{2019})$. Hu (2014) showed that cognitive load occurred in all geometry materials. Cognitive load is categorized into three types based on the cognitive load theory: intrinsic cognitive load, extraneous cognitive load, and germane cognitive load (Paas, Tuovinen, Tabbers, \& Van Gerven, 2003; Sweller, 2010).

Intrinsic cognitive load deals with the complexity of the information that needs to be processed by our memory (Kirschner et al., 2018). Intrinsic cognitive load in the learning process refers to the level of complexity in the teaching materials given (Sweller \& Chandler, 2016). The complexity of the material comes from the learning material itself and its complexity is determined by the prior knowledge required (Sweller, 2010). Prerequisite material is needed to find the unknown side's size of a similar triangle, such as comparisons, multiplications, and linear equations. Students who master the prerequisite materials will experience a small intrinsic cognitive load compared to students who have not mastered the prerequisite material (Sweller et al., 2011). Sweller (2010) argued that germane cognitive load is the capacity of working memory that is devoted to manage and organize intrinsic cognitive load. Germane cognitive load assists learners in comprehending the content of the learning materials. Germane cognitive load leads to productive efforts to construct new knowledge.

Extraneous cognitive load in the learning process is determined by the presentation technique of materials (Sweller, 2010). According to Sweller, the learning process should minimize extraneous cognitive load. Extraneous cognitive load can be caused by split attention (Sweller et al., 2011). Split attention occurs when attention must be divided between multiple sources of visual information that are all essential for understanding (Nurjanah \& Retnowati, 2018). Figure 1 shows an example of split attention and non-split attention.

Learning by the goal-free problem is suggested since it might minimize extraneous cognitive load (Ayres, 1993). A goal-free problem is a presentation technique on problemsolving with the design that eliminates the goal or final destination of the problem (Sugiman, Retnowati, Ayres, \& Murdanu, 2019). In learning using a goal-given problem, the form of a question is in line with "Determine the value of $x$ !". Whereas, in learning using goal-free problems, the instruction is in line with "Find the values as many as possible!" (Sweller, 2010). Studies have shown that this technique evidently decreases students' cognitive loads (Paas, Camp, \& Rikers, 2001; Sugiman et al., 2019). 


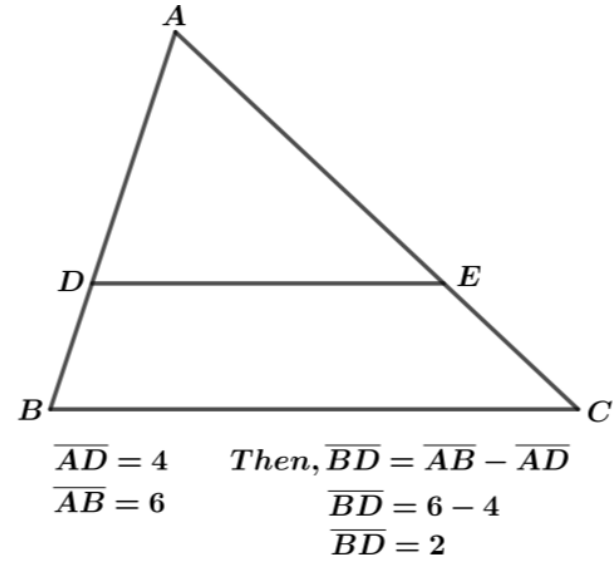

(a)

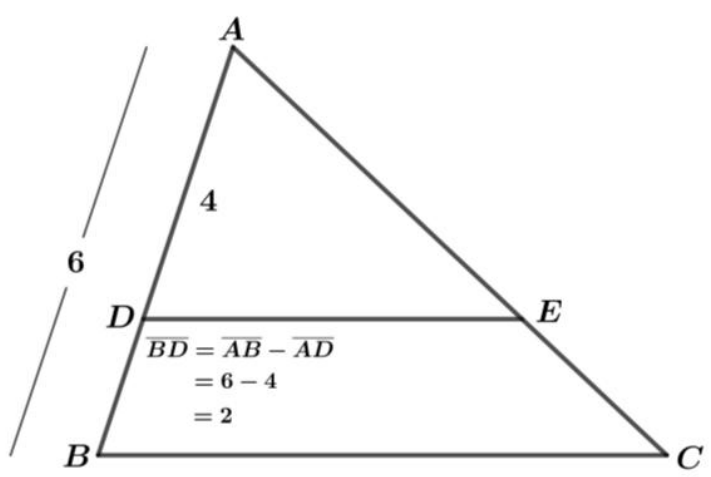

(b)

Figure 1. Example of (a) split attention and (b) non-split attention presentation

Research on goal-free problems began with an experiment conducted by Sweller and Levine (1982) using puzzles and maze problems. The research showed that students would learn more optimally if the goal of the problem is eliminated rather than when the goal is given. In the experiment, the actual labyrinth can be solved in simple steps, but students who are aware of the goal will find more wrong steps than students who are not given the goal. Further studies have also informed that goal-free problems facilitate students to solve problems flexibly and enhance their problem-solving skills, which can be beneficial for classroom implications (Maulidya, Hasanah, \& Retnowati, 2017; Youssef-Shalala, Ayres, Schubert, \& Sweller, 2014).

Social interaction between students in a collaborative manner is often used by teachers to improve their ability to understand concepts in solving a mathematical problem (Irwansyah \& Retnowati, 2019). Social interaction in the form of group learning is built from learning in class, social group friendship, communication, and frequent teamwork (Tindale, Smith, Dykema-Engblade, \& Kluwe, 2012). Collaborative learning is a learning method that allows students to work together in a small group to learn academic content (Slavin, 2014). Students in collaborative groups share information, search for meanings and solutions, and maintain a shared understanding of the problem (Iiskala, Vauras, Lehtinen, \& Salonen, 2011). Collaborative learning occurs when a learning task is too complex if solved individually (Kirschner et al., 2018; Malmberg, Haataja, Seppänen, \&Järvelä, 2019; Mønster, Håkonsson, Eskildsen, \& Wallot, 2016). Providing explanations to group members do not only allow the exchange of ideas but also encourage the discovery of findings which underlie a principle (Webb, 1991). The process of providing explanations can encourage students who provide explanations about clarifying, reorganizing, and completing the material and developing new perspectives (Webb, 1991). This is important in order to create a condition which ensures positive interaction to occur between students so that they have the same opportunities to help other students, and that condition must be consistent (Retnowati et al., 2010).

Collaborative learning has advantages when it is used in learning fewer complex problems (Retnowati, Ayres, \& Sweller, 2017). Collaborative learning also has several advantages in the academic field. According to Laal and Ghodsi (2012), collaborative learning (1) promotes critical thinking skills, (2) involves students actively in a learning process. Meanwhile, according to Hill \& Hill (1993), the advantages of collaborative learning are that it (1) develops a deeper understanding, (2) makes learning more fun, (3) develops leadership skills among students, (4) enhances positive attitude, and (5) 
increases self-esteem. Indeed, it is often heard that collaborative learning sounds beneficial.

Nevertheless, collaborative learning may not always be effective. Putting students into groups and giving them an assignment does not guarantee that they will work together and engage in effective collaborative learning behavior (Soller, 2001). Regarding to strategy worked example, collaborative learning was no more effective than individual learning in terms of problem-solving and cognitive load (Irwansyah \& Retnowati, 2019). Individual learning was also superior to collaborative learning when using the worked example method (Retnowati et al., 2017). However, controlled collaboration in learning is no guarantee for success. In many cases, individual performance was lower than collaborative performance, which means that student's memorizing abilities in collaborative learning is poorer than students in individual learning (Kirschner, Paas, \& Kirschner, 2009).

Learning by goal-free problems might minimize extraneous cognitive load (Ayres, 1993). Goal-free problems are thought to be able to provide a small cognitive load in triangle similarity. More specifically, this study was conducted to determine the effectiveness of goal-free problems using collaborative learning. Therefore, this research is conducted to test whether the goal-free problems is effective for novice learners, as well as to determine the effectiveness of collaborative learning in the triangle similarity material. The result of this experiment can be used as an alternative or better choice for mathematics learning that is oriented towards developing problem-solving abilities by novice learners.

\section{Research Methods}

\section{Research design}

The study examined the effectiveness of goal-free problems using a factorial design: 2 presentation techniques (goal-free vs. goal-given problem solving) $\mathrm{x} 2$ groupings (individual vs. collaborative). Grouping in this current study is defined as a strategy of learning, whether thinking alone (individually) or based on discussion results (collaborative). Based on this, students were allocated randomly into one of the following conditions: (1) goal-free problems in individual learning, (2) goal-free problems in collaborative learning. (3) goal-given problems in individual learning, and (4) goal-given problems in collaborative learning.

\section{Participant}

The research sample for the experiment in this study consisted of one-hundred eleven eighth-graders from four classrooms in a junior high school in Yogyakarta, Indonesia. These students had similar conditions in the age range between 12-13 years old, studied using the same national competency-based curriculum, and novice learner (not learning triangle similarity material yet). The details of the sample size can be seen in Table 1.

Table 1

Sample Size

\begin{tabular}{ccc}
\multicolumn{2}{c}{ Category } & $\mathrm{N}$ \\
\hline \multirow{2}{*}{ Goal-free } & Individual & 27 \\
& Collaborative & 26 \\
& Total & $\mathbf{5 3}$ \\
\hline \multirow{2}{*}{ Goal-given } & Individual & 28 \\
& Collaborative & 30 \\
& Total & $\mathbf{5 8}$ \\
\hline
\end{tabular}




\section{Procedure of the study}

The experiment used an authentic classroom and consisted of four consecutive phases: introductory, learning phase, retention test, and transfer test. The introductory phase provided the basic of the similarity concept: (1) the corresponding angle on both planes has the same size, and (2) the ratio of the corresponding edge is equal. This phase lasted for 15 minutes. In the learning phase, students were asked to solving ten problems. In this phase, students were randomly assigned to follow one of the learning designs. Students in the collaborative class worked in groups of 3-4 participants, while students in the individual class worked individually. The learning phase lasted for 48 minutes. In the retention and transfer test phases, students worked on five questions. The structure of problems in the retention test was similar to the learning phase. However, the structure of problems in the transfer test had a different structure and required a proper strategy to solve them. The retention phase lasted for 20 minutes and the transfer test took 30 minutes. Students worked individually in the retention and transfer tests.

\section{Instrument}

The instruments were arranged in the form of A5-sized booklets in a way that one page contained only one question. Students were asked to write their answers on the question sheets. These sheets were also allowed as a medium for counting by students. Students were not permitted to use calculators or other electronic items. This was done to reduce data bias. The correct answer was given a grade of 1 , the wrong answer was given a value of 0 , while the partially correct answer was given a value of 0.5 . The maximum number of scores that students obtained was 5 and the minimum score was 0 .

Goal-free problems allowed students to train their problem-solving skills by giving them the opportunity to freely look for values by using the available information. Without the need to determine the sub-goal, students can work on the problem directly compared to when they attempt to solve goal-given problems. An example of a goal-free problem presentation technique can be seen in Figure 2 .

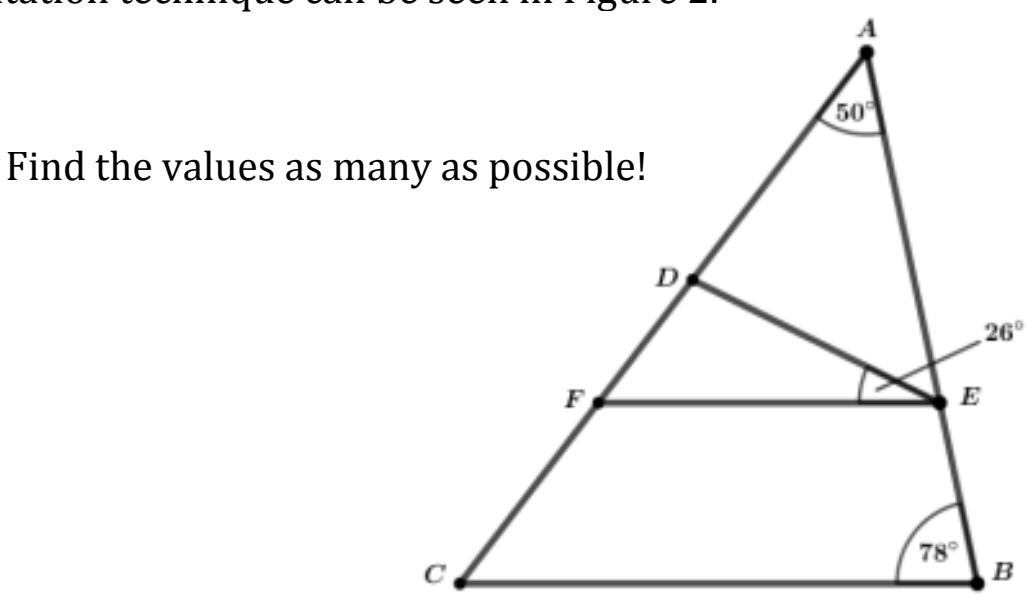

Figure 2. Example of the goal-free problem presentation technique

The steps to solving the example of a goal-free problem in Figure 2 are presented in Table 2. 
Table 2

The six steps for finding the solution to a goal-free problem

1) Give a name for each vertex to make it easier to determine the solution

2)

3)
4)

6)

$$
\begin{aligned}
\frac{A F}{A C} & =\frac{A E}{A B} \\
\frac{A F}{15} & =\frac{8}{12} \\
A F & =\frac{8 \times 15}{12} \\
C F & =10 \\
& =15-A F \\
& =5
\end{aligned}
$$

This study used two sources of data. The first one was used to measure the cognitive load data and the other was to measure the ability to transfer knowledge. The instrument for measuring student cognitive load data was a rating question developed using a ninepoint Likert's scale. Likert's scale used was adapted from Retnowati (2010). There were two types of questions used in this research (individual strategy and collaborative strategy). The question used in the individual strategy was "how difficult did you solve a problem individually?", while the question for the collaborative strategy was "how difficult did you solve a problem after collaborating?". Nine alternative answer points ranged from 1 to 9 with " 1 = Too easy" and "9 = Too difficult." There were ten rating questions in the transfer test phase, five rating questions in the lower problem-solving skill test or near transfer test, and five rating questions in the higher problem-solving skill test or far transfer test.

A transfer is the ability to solve new and unfamiliar problems by applying knowledge that has been learned (Mayer, 2002). This ability is used to recall material that had been learned to solve a new problem. In other words, problem-solving is a part of capability transfer. Because of that, transfer of test can be used to measure the effectiveness of goal free problems. It could be understood by linking cognitive levels with Taxonomy Bloom (Mayer, 2002). Bloom's Taxonomy is a triangular hierarchical structure of thinking ability from a low level to a higher level. According to Krathwohl (2002), Bloom's Taxonomy consists of six levels. These hierarchy levels range from low to high, namely: remembering, understanding, applying, analyzing, evaluating, and creating.

A Transfer is divided into two kinds: near transfer and far transfer. A near transfer is the ability to remember certain material learned in the learning process. The cognitive process in the near transfer test is in recognizing and remembering or recalling. For example, students can calculate " $8+5=\ldots$.. after they have learned about an addition of operation. A far transfer is a transfer of ability that uses and applies previous knowledge to solve new problems. Unlike the near transfer which only involves the lowest level of Bloom's Taxonomy, far transfer involves all components of Bloom's Taxonomy. For example, students are able to use the addition theorem to solve multiplication problems because multiplication is repetitive addition.

The instrument to measure data on knowledge transfer capability was used in two phases, namely near transfer test and far transfer test. The near transfer test was given earlier than the far transfer test. The near transfer test requires students to work on five descriptive questions with a structural similarity to the questions they have learned in the learning phase. Students were asked to determine the length of the side of $x$ in the near transfer test phase. 
Far transfer tests require students to work on five questions with different question structures and there are no similarities to the learning phase. The problem in this phase consists of the application of several theorems such as the congruence, area application, and the Pythagorean Theorem. In this phase, students were asked to determine the $x$ side length.

\section{Results and Discussion}

This study used ANCOVA to examine the hypothesis, using the prior mathematics test result as the covariate. Covariates are used to eliminate or reduce noise in data analysis caused by variables other than the variables under study. Thus, the effects of the variables

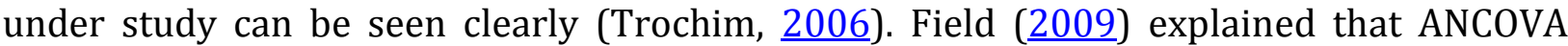
produces an F-ratio that compares the number of systematic variants with unsystematic variants. The F-ratio is compare between how good the model being tested and how bad the model is. A basic assumption was made before analyzing the data. The experiment data were analyzed with a significance level of 0.05. Data analysis is summarized in Table 3.

Table 3

Statistic of :(a) presentation technique, (b)grouping,

(a)

\begin{tabular}{|c|c|c|c|c|c|c|}
\hline \multirow{3}{*}{ Variable } & \multicolumn{6}{|c|}{ Presentation Technique } \\
\hline & \multirow{2}{*}{ Sig. } & \multicolumn{2}{|c|}{ Goal-free } & \multicolumn{2}{|c|}{ Goal-given } & \multirow{2}{*}{ Conclusion } \\
\hline & & $M$ & $S D$ & $M$ & $S D$ & \\
\hline \multicolumn{7}{|l|}{ Transfer Ability } \\
\hline - Near Transfer & 0.003 & 2.7547 & 1.20744 & 1.8793 & 0.96568 & Goal-free $>$ Goal-given \\
\hline - $\quad$ Far Transfer & 0.000 & 1.4623 & 0.96501 & 0.3707 & 0.55851 & Goal-free $>$ Goal-given \\
\hline \multicolumn{7}{|l|}{ Cognitive Load } \\
\hline - Learning & 0.000 & 4.7396 & 1.85983 & 6.0052 & 1.38873 & Goal-free $<$ Goal-given \\
\hline - Near Transfer & 0.000 & 6.2453 & 1.92459 & 7.9274 & 1.49594 & Goal-free $<$ Goal-given \\
\hline - Far Transfer & 0.007 & 7.7057 & 1.76138 & 8.7931 & 0.79115 & Goal-free $<$ Goal-given \\
\hline
\end{tabular}

(b)

\begin{tabular}{|c|c|c|c|c|c|c|}
\hline \multirow{3}{*}{ Variable } & \multicolumn{6}{|c|}{ Grouping } \\
\hline & \multirow{2}{*}{ Sig. } & \multicolumn{2}{|c|}{ Individual } & \multicolumn{2}{|c|}{ Collaborative } & \multirow{2}{*}{ Conclusion } \\
\hline & & $\overline{\boldsymbol{x}}$ & $S D$ & $\bar{x}$ & $S D$ & \\
\hline \multicolumn{7}{|l|}{ Transfer Ability } \\
\hline - Near Transfer & 2.84 & 2.4091 & 1.31969 & 2.1875 & 0.99801 & Individual $>$ Collaborative \\
\hline - $\quad$ Far Transfer & 0.109 & 1.0182 & 0.90760 & 0.7679 & 0.98148 & Individual $>$ Collaborative \\
\hline \multicolumn{7}{|l|}{ Cognitive Load } \\
\hline - Learning & 0.002 & 4.9218 & 1.72741 & 5.8714 & 1.64037 & Individual $<$ Collaborative \\
\hline - $\quad$ Near Transfer & 0.000 & 6.3636 & 2.12571 & 7.9179 & 1.29153 & Individual $<$ Collaborative \\
\hline - $\quad$ Far Transfer & 0.359 & 8.1564 & 1.53608 & 8.3893 & 1.35401 & Individual $<$ Collaborative \\
\hline
\end{tabular}

\section{Data analysis of cognitive load during the learning phase}

There is a significant main effect of the presentation technique with $F(1,109)=$ 15.050, $M S E=36.926, p=0.000$, and $\eta_{\mathrm{p}}{ }^{2}=0.124$. This result confirmed the hypothesis that goal-free problems facilitate more effectively than goal-given problems. A significant main effect of grouping is also found with $F(1,109)=9.865, M S E=24.203, p=$ 0.002 , and $c_{p}{ }^{2}=0.085$. This result confirmed the hypothesis that collaborative learning is significantly higher than individual learning. However, there is no interaction effect between the presentation technique and groupings with $F(1,109)=2.617$ and $p>0.05$. The estimated marginal means of cognitive load during the learning phase is illustrated in Figure 3. 


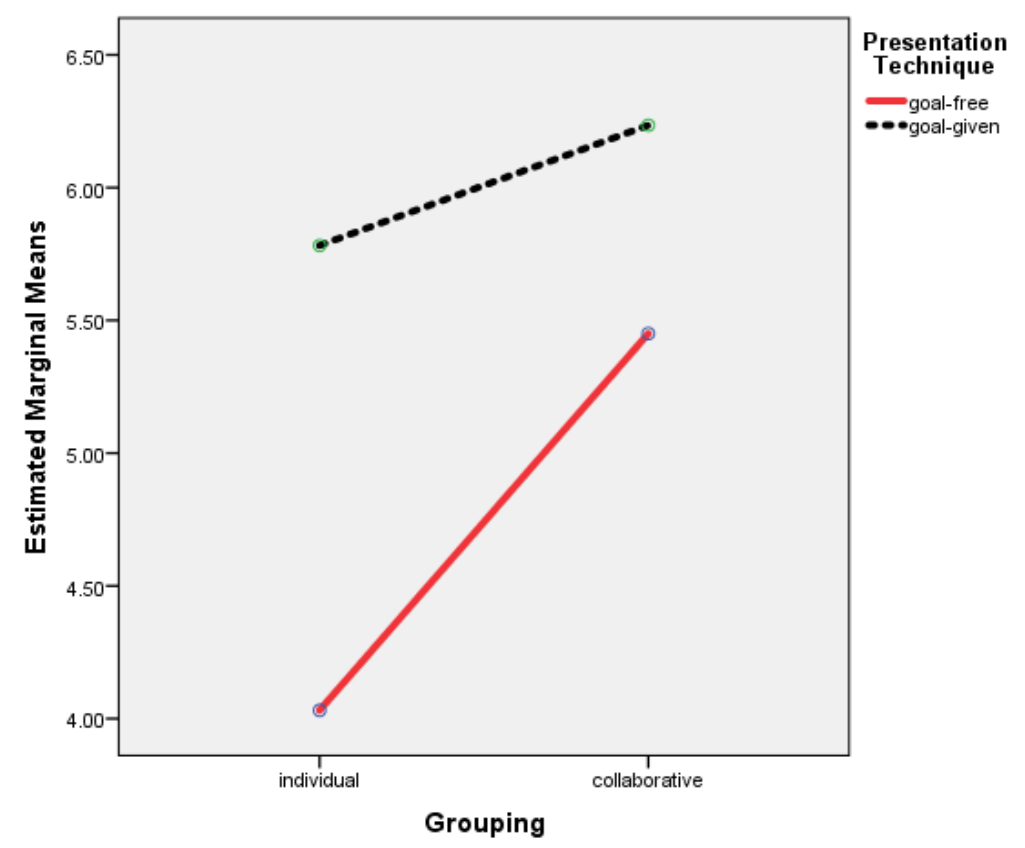

Figure 3. Cognitive load during the learning phase

\section{Data analysis of retention test score}

The result of abilities analyst of retention test got a significant main effect in presentation technique with $F(1,109)=9.051, M S E=10.446, p=0.003$, and $\eta_{p}{ }^{2}=0.079$. The result confirmed the hypothesis that the learning process presented in goal-free problems facilitates better significantly than that in goal-given problems. A non-significant main effect of groupings on the ability of retention test was found with $F(1,109)=$ 1.160 and $p>0.05$. This confirmed that there is no significant difference between individual learning and collaborative learning on the retention test scores. There is no interaction effect between presentation technique and groupings with $F<1$ and $p>0.05$. The estimated marginal means of retention test or near transfer can be seen in Figure 4 .

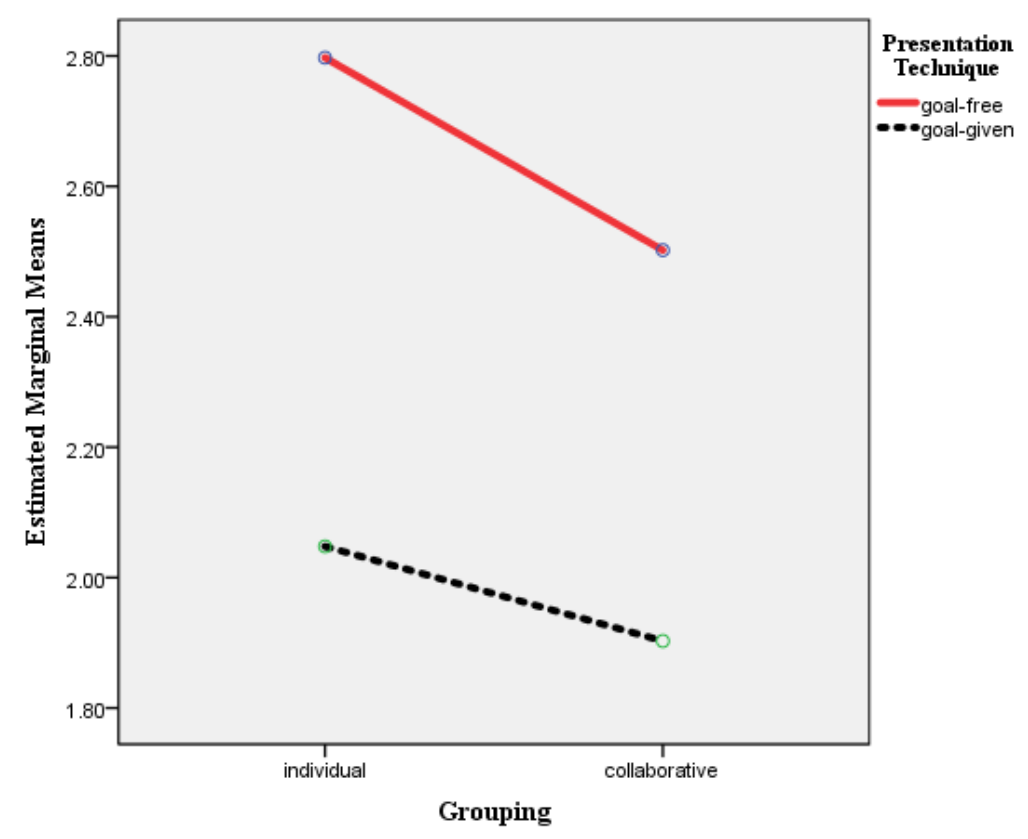

Figure 4. Estimated marginal means of retention 


\section{Data analysis of transfer test}

The transfer test scores analysis showed a significant main effect of presentation technique on the transfer test scores with $F(1,109)=37.797, M S E=22.430, p=$ 0.000 , and $\eta_{p}{ }^{2}=0.263$. It confirmed the hypothesis that present learning in goal-free problems facilitates more effectively than that in goal-given problems. Unlike the main effect of presentation technique, the main effect of groupings on transfer test is not found with $F(1,109)=1.547$ and $p>0.05$. Thus, the hypothesis that learning in a collaborative manner is more effective than individual learning is rejected. Besides that, the interaction effect between presentation technique and grouping on the transfer test score is also not found with $F(1,109)=1$ and $p>0.05$. The estimated marginal means of far transfer can be seen in Figure 5.

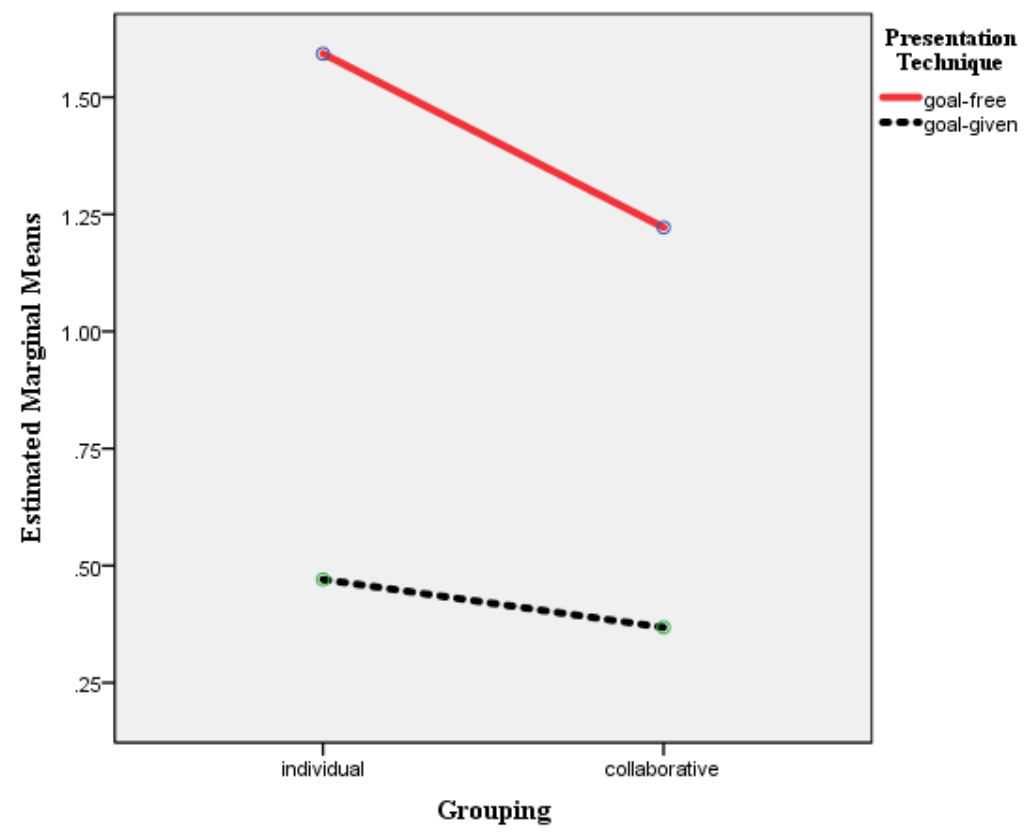

Figure 5. Estimated marginal means of transfer

\section{Data analysis of cognitive load during retention test}

There is a significant main effect of presentation technique on cognitive load during the retention test with $F(1,109)=21.319, M S E=50.564, p=0.000$, and $\eta_{\mathrm{p}}{ }^{2}=0.167$. This result confirmed the hypothesis that present learning in goal-free problems significantly facilitates better compared to the goal-given ones. There is also a significant main effect of grouping on cognitive load during the retention test with $F(1,109)=$ $27.114, M S E=64.308, p=0.000$, and $\eta_{\mathrm{p}}{ }^{2}=0.204$. This result suggests that the learning in collaboratively is significantly better than learning individually. However, there is no interaction effect between presentation technique and groupings with $F<1$ and $p>0.05$. The estimated marginal means of cognitive load during the retention test or near transfer test is illustrated in Figure 6.

\section{Data analysis of cognitive load during transfer test}

The significant main effect of the presentation technique is indicated by the cognitive load during transfer test with $F(1,109)=7.670, M S E=13.126, p=0.007$, and $\eta_{\mathrm{p}}{ }^{2}=0.067$. This confirmed the hypothesis that goal-free problems are better than goal-given problems for the cognitive load during the transfer test. However, the significant main effect of grouping on the cognitive load transfer test is not found with $F(1,109)=0.849$ and $p>$ 
0.05. This means that there is no significant difference between individual and collaborative learning on cognitive load during a transfer test phase. An interaction effect between presentation technique and grouping is not revealed with $F<1$ and $p>0.05$. The estimated marginal mean of cognitive load during far transfer test is depicted in Figure 7.

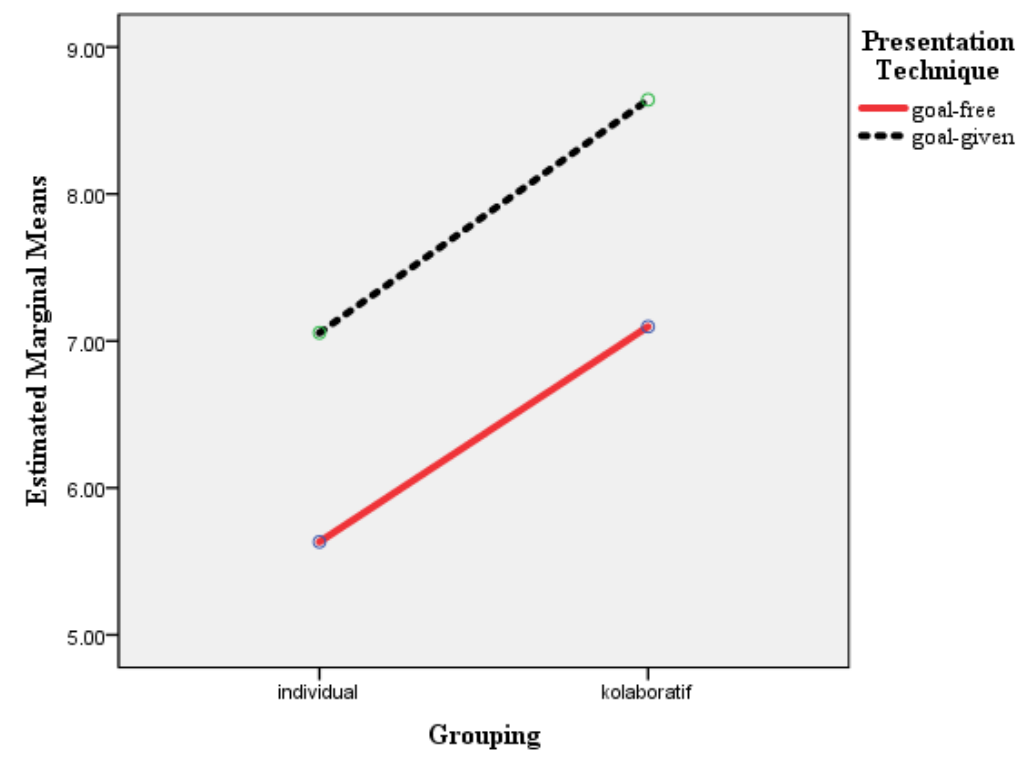

Figure 6. Cognitive load during the retention

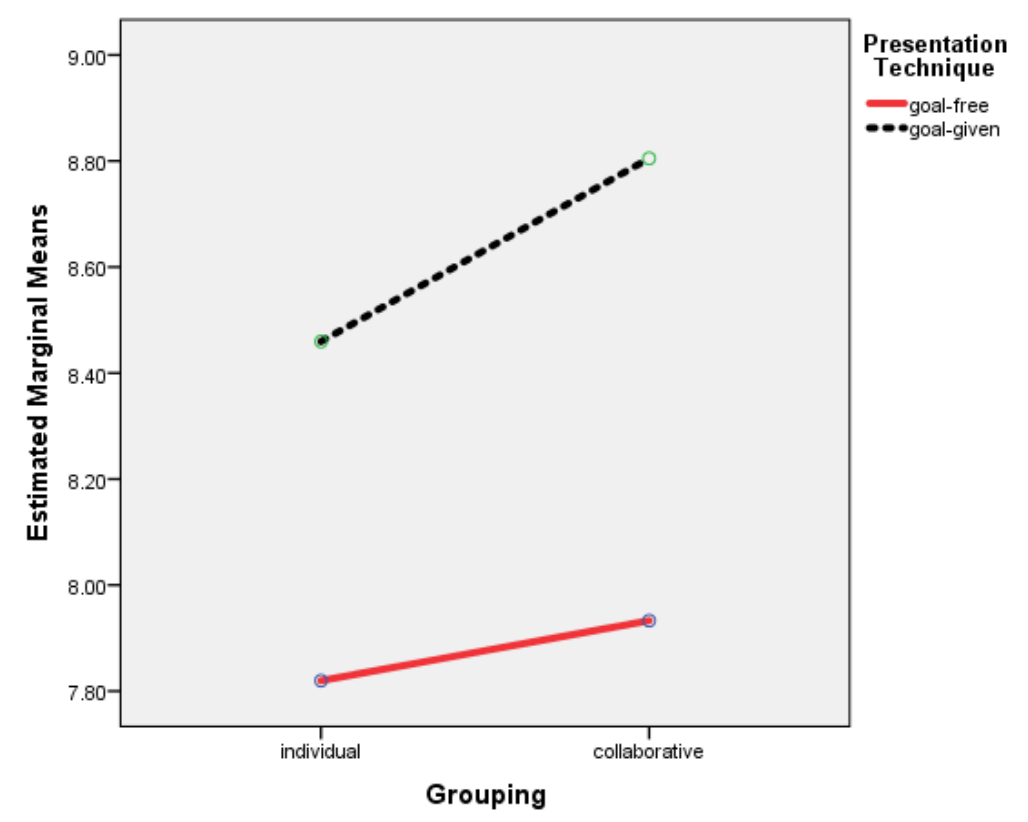

Figure 7. Cognitive load during transfer test

The current study investigated the effectiveness of presenting triangle similarity as described in the method above. An experiment was conducted using a factorial design: 2 presentation technique (goal-free vs. goal-given problems) x 2 groupings (collaborative vs. individual learning). The combination of two factorial design resulted in four classes: (1) goal-free problem in individual learning; (2) goal-free problem in collaborative learning; (3) goal-given problem in individual learning; (4) goal-free problem in collaborative 
learning. Each participant was randomly selected to join one of those classes. Students' transfer ability and cognitive load were dependent variables in this experiment, whereas presentation technique and groupings were the independent variables. Students' transfer ability was measured in the retention and transfer test phase. Cognitive load was measured in each phase, the learning phase, retention test, and transfer test. Based on the cognitive load theory, this study proposed the hypotheses: (1) goal-free problems are more effective than goal-given problems; (2) collaborative learning is more effective than individual learning; and (3) goal-free problems by collaborative learning is more effective than by individual learning.

The result showed that students who learn using goal-free problems had scored higher than students who learn using goal-given problems. This outcome is also similar to the previous experiment conducted by Ayres (1993). Ayres explained that goal-free problems could improve learning outcomes as goal-free problems are able to reduce the heavy cognitive load by using means-ends analysis strategies. The results of the study are in accordance with the literature review conducted by Maulidya et al., (2017), which found that goal-free problem could facilitate students to enhance their problem-solving skills. Goal-free problems provide an opportunity for students to use limited working memory capacity to focus on the constructed knowledge (Sweller et al., 2011).

A higher score in transfer ability means that students have small cognitive load; hence, the limited working memory capacity can be maximized to build or construct knowledge. In other words, if the students' score in transfer ability is low, they will have a higher cognitive load, meaning that the working memory capacity may not be maximized to build or construct knowledge. The previous research conducted by Sweller et al., (2011) showed that the cognitive load is inversely proportional to the students' transfer ability. Low cognitive load on instruction has an impact on the student's ability to receive when learning increases. This experiment showed that students' cognitive load that follow goalgiven problems is higher than students who follow goal-free problems. In contrast, the score of transfer tests of students in goal-given problems was lower than the goal-free problems. In other words, the result of data analysis is in line with previous research by (Sugiman et al., 2019).

The second hypothesis to be tested in this experiment is whether mathematics learning in collaboration facilitates learning to be more effective than individual learning. The result of the data analysis showed that no significant main effect on the ability retention and transfer test. Thus, the hypothesis is rejected. Similar results were found in the previous experiment using the worked example approach by (Retnowati et al., $\underline{2010}$ ). The result rejected some experiment that expressed collaborative learning is superior to individual learning (P. A. Kirschner et al., 2018; Retnowati et al., 2017). In other words, the data analysis rejected the second hypothesis.

As the second hypothesis was rejected by the data analysis, as a consequence, the third hypothesis could not be proved. Moreover, the analysis showed that students who learned similarity individually scored significantly better in the transfer test than those who studied collaboratively. It was found that the presentation of the material using goalfree problems was effective for both groupings.

The result of this experiment does not support the second hypothesis. This confirms another experiment that complex problems will be more effective if learned individually rather than collaboratively (Retnowati et al., 2017). Furthermore, there are many methods of collaborative learning. This study did not use a specific method of collaborative learning. On the contrary, according to Retnowati, Ayres, and Sweller (2018), a jigsaw method of collaboration is more appropriate than general collaborative learning for complex 
problems. Further study is needed to find out other methods of collaborative learning that are effective for studying complex problems.

In this experiment, the researchers faced some limitations that might affect the condition of the research conducted. The time allocation ( $3 \times 40$ minutes) was still lacking in order to achieve maximum results. In addition, research conducted during the last schedule resulted in the addition of cognitive load on students, which eventually made some students took the learning reluctantly. Some students also forgot to fill out some instruments. This became a problem as incomplete instruments could not be included in the analysis. As a result, there were only one hundred and eleven data of students analyzed for this study. However, the results of this study can be applied to students in schools.

\section{Conclusion}

The findings of this study provide several suggestions. Learning with goal free problems can be used as an alternative for developing problem-solving abilities by novice learners. Furthermore, individual learning is more recommended for the development of problem-solving abilities for complex problems. Another suggestion is that collaborative learning is not always effective for novice learners if the learning outcomes are viewed from the transfer ability in problem solving. Research on goal free problems using different mathematics learning materials needs to be followed up so that the application of goal free problems is wider and more specific.

\section{Acknowledgment}

We would like to sincere gratitude to the students and school of SMP N 9 Yogyakarta who have participated in this research.

\section{Bibliography}

Ayres, P. L. (1993). Why Goal-Free Problems Can Facilitate Learning. Contemporary Educational Psychology, 18(3), 376-381. https://doi.org/10.1006/ceps.1993.1027

BSNP. (2006). Standar isi untuk satuan pendidikan dasar dan menengah. Jakarta: BSNP

Field, A. (2009). Discovering statistics using SPSS. London: Sage Publication.

Hill, S., \& Hill, T. (1993). The Collaborative class room. A guide to co-operative learning. Amadale, Vic: Eleanor Curtin Publishing

Hu, F. T., Ginns, P., \& Bobis, J. (2014). Does Tracing Worked Examples Enhance Geometry Learning?.Australian Journal of Educational \& Developmental Psychology, 14, 45-49.

Iiskala, T., Vauras, M., Lehtinen, E., \& Salonen, P. (2011). Socially shared metacognition of dyads of pupils in collaborative mathematical problem-solving processes. Learning and Instruction, 21(3), 379-393. https://doi.org/10.1016/i.learninstruc.2010.05.002

Irwansyah, M. F., \& Retnowati, E. (2019). Efektivitas worked example dengan strategi pengelompokan siswa ditinjau dari kemampuan pemecahan masalah dan cognitive load. Jurnal Riset Pendidikan https://doi.org/10.21831/JRPM.V6I1.21452

Kirschner, F., Paas, F., \& Kirschner, P. A. (2009). Individual and group-based learning from complex cognitive tasks: Effects on retention and transfer efficiency. Computers in Human Behavior, 25(2), 306-314. https://doi.org/10.1016/j.chb.2008.12.008

Kirschner, P. A., Sweller, J., Kirschner, F., \& Zambrano, J. R. (2018). From Cognitive Load Theory to Collaborative Cognitive Load Theory. International Journal of ComputerSupported Collaborative Learning, 13(2), 213-233. https://doi.org/10.1007/s11412- 
018-9277-y

Krathwohl, D. R. (2002). A revision of bloom's taxonomy: An overview. Theory into Practice, 41(4), 212-218. https://doi.org/10.1207/s15430421tip4104 2

Laal, M., \& Ghodsi, S. M. (2012). Benefits of collaborative learning. Procedia - Social and Behavioral Sciences, 31, 486-490. https://doi.org/10.1016/j.sbspro.2011.12.091

Malmberg, J., Haataja, E., Seppänen, T., \& Järvelä, S. (2019). Are we together or not? The temporal interplay of monitoring, physiological arousal and physiological synchrony during a collaborative exam. International Journal of Computer-Supported Collaborative Learning, 14(4), 467-490. https://doi.org/10.1007/s11412-019$\underline{09311-4}$

Maulidya, S. R., Hasanah, R. U., \& Retnowati, E. (2017). Can goal-free problems facilitating students' flexible thinking? AIP Conference Proceedings, 1868. https://doi.org/10.1063/1.4995128

Mayer, R. E. (2002). Rote Versus Meaningful Learning. Theory Into Practice, 41(4), 226-232. https://doi.org/10.1207/s15430421tip4104 4

Miller, G. A. (1956). The magical number seven, plus or minus two: some limits on our capacity for processing information. Psychological Review, 63(2), 81-97. https://doi.org/10.1037/h0043158

Mønster, D., Håkonsson, D. D., Eskildsen, J. K., \& Wallot, S. (2016). Physiological evidence of interpersonal dynamics in a cooperative production task. Physiology and Behavior, 156, 24-34. https://doi.org/10.1016/j.physbeh.2016.01.004

Nurjanah, A., \&Retnowati, E. (2018). Analyzing the extraneous cognitive load of a 7 th grader mathematics textbook. Journal of Physics: Conference Series. https://doi.org/10.1088/1742-6596/1097/1/012131

Paas, F., Camp, G., \& Rikers, R. (2001). Instructional compensation for age-related cognitive declines: Effects of goal specificity in maze learning. Journal of Educational Psychology, 93(1), 181-186. https://doi.org/10.1037/0022-0663.93.1.181

Paas, F., Tuovinen, J. E., Tabbers, H., \& Van Gerven, P. W. M. (2003). Cognitive Load Measurement as a Means to Advance Cognitive Load Theory. Educational Psychologist, 38(1), 63-71. https://doi.org/10.1207/S15326985EP3801 8

Peterson, L. R., \& Peterson, M. J. (1959). Short-Term Retention of Individual Verbal Items. Journal of Experimental Psychology, 58(3), 193-198. https://doi.org/10.1037/h0049234

Retnowati, E., Ayres, P., \& Sweller, J. (2010). Worked example effects in individual and group work settings. Educational Psychology, 30(3), 349-367. https://doi.org/10.1080/01443411003659960

Retnowati, E., Ayres, P., \& Sweller, J. (2017). Can collaborative learning improve the effectiveness of worked examples in learning mathematics? Journal of Educational Psychology, 109(5), 666-679. https://doi.org/10.1037/edu0000167

Retnowati, E., Ayres, P., \& Sweller, J. (2018). Collaborative learning effects when students have complete or incomplete knowledge. Applied Cognitive Psychology, 32(6), 681692. https://doi.org/10.1002/acp.3444

Schoenfeld, A. H. (2016). Learning to Think Mathematically: Problem Solving, Metacognition, and Sense Making in Mathematics (Reprint). Journal of Education. https://doi.org/10.1177/002205741619600202

Slavin, R. E. (2014). Cooperative learning and academic achievement: Why does groupwork work? Anales de Psicologia, 30(3), 785-791. https://doi.org/10.6018/analesps.30.3.201201

Soller, A. (2001). Supporting Social Interaction in an Intelligent Collaborative Learning 
System. International Journal of Artificial Intelligence in Education, 12, 40-62.

Sugiman, S., Retnowati, E., Ayres, P., \& Murdanu, M. (2019). Learning Goal-Free Problems: Collaboratively or Individually? Jurnal Cakrawala Pendidikan, 38(3), 590-600. https://doi.org/10.21831/cp.v38i3.26914

Sweller, J. (2010, June 23). Element interactivity and intrinsic, extraneous, and germane cognitive load. Educational Psychology Review, Vol. 22, pp. 123-138. https://doi.org/10.1007/s10648-010-9128-5

Sweller, J., Ayres, P., \& Kalyuga, S. (2011). Cognitive Load Theory: Explorations in the Learning Sciences, Instructional Systems and Performance Technologies Series Editors. Retrieved from http://www.springer.com/series/8640

Sweller, J., \& Chandler, P. (2016). Why Some Material Is Difficult to Learn. Cognition and Instruction, (September 1994). https://doi.org/10.1207/s1532690xci1203

Sweller, J., \& Levine, M. (1982). Effects of goal specificity on means-ends analysis and learning. Journal of Experimental Psychology: Learning, Memory, and Cognition, 8(5), 463-474. https://doi.org/10.1037/0278-7393.8.5.463

Tasari, J. D. (2011). Matematika Jilid 3 untuk SMP dan MTs Kelas IX. Jakarta: Pusat Kurikulum dan Perbukuan Pendidikan Nasional.

Tindale, R. S., Smith, C. M., Dykema-Engblade, A., \& Kluwe, K. (2012). Good and bad group performance: Same process-different outcomes. Group Processes \& Intergroup Relations, 15(5), 603-618. https://doi.org/10.1177/1368430212454928

Trochim, W. M. (2006, October 20). Covariance design. Retrieved from http://www.socialresearchmethods.net/kb/expcov.php

Webb, N. M. (1991). Task-Related Verbal Interaction and Mathematics Learning in Small Groups. Journal for Research in Mathematics Education, 22(5), 366. https://doi.org/10.2307/749186

Youssef-Shalala, A., Ayres, P., Schubert, C., \&Sweller, J. (2014). Using a general problemsolving strategy to promote transfer. Journal of Experimental Psychology: Applied, 20(3), 215-231. https://doi.org/10.1037/xap0000021 